taught an absurd hypothesis, and blindly refused to listen to those who suggested that the question should be scientifically investigated. I should be indelted to Dr. Wilks if he would point out what fallacies underlie the above arguments, as I am anxious, as a pathologist, to arrive at the exact truth of this important point in the subject.
I am, Sirs, faithfully yours,

Feb. 1889.

H. H. TAYLOR.

\section{RHEUMATISM AND CHOREA.} To the Editors of THE LANCET.

SIRs,-Dr. Herringham, in his letter on the above subject which appears in your issue of Feb. 2nd, expresses his strong disapproval of such phrases as that chorea is a manifestation of rheumatism, but it secms to me that his arguments really support that view. All that is contended by those who speak of chorea as a manifestation of rheumatism is that the unknown poison of rheumatism, acting upon the nervous system, is the most common cause of the condition which we call chorea, and that endocarditis is frequently associated with chorea, because the heart is so frequently attacked in the course of a rheumatic attack ; but the rheumatic poison is not the sole cause of chorea, any more than it is the sole cause of endocarditis, of pericarditis, of arthritis, or of erythema. It is not by the frequent occurrence of chorea in those who have suffered from articular rheumatism that the strongest evidence of the rheumatic nature of chorea is afforded; but by the frequent occurrence of chorea as one element in a series of rheumatic events in childhood, by the simultaneous or consecutive appearance of a group of phenomena, each of which individually may be due to other causes, but which, when they are met with in association, may reasonably be held to indicate the working of that cause which is common to them all. How else is to be explained the occasional association of chorea with erythema, with endocarditis and nodule formation, in cases in which the joints may or may not be affected? Is there any sufficient ground for separating the chorea from the other members of the series, and for supposing that whereas the other events are manifestations of the rheumatic process, the relation of chorea to that process is of a different character?

If the view which I have endeavoured to present, and which has been so well expressed by Sir Dyce Duckworth, Drs. Cheadle, Barlow, Stephen Mackenzie, and others, is the correct one, we cannot speak of chorea as a cause of endocarditis, as Dr. Herringham does; but of the rheumatic poison as the cause of both the nervous symptoms and the endocarditis, as well as of the other manifestations, if such are present. With Dr. Herringham's interpretation of the significance of the fact that chorea is not a common antecedent of articular rheumatism, I most cordially agree.

I am, Sirs, yours obediently,

Chandos-st., W., Feb. 4th, 1889 . ARCHibald E. Garrod.

\section{"XEROSTOMIA"-A TERM SUGGESTED FOR THE AFFECTION KNOWN AS DRY MOUTH. To the Editors of THE LANCET.}

SIRs,-The first sentence of Dr. Hadden's letter in your last issue runs: "In the last volume of the Clinical Society's Transactions two cases of dry mouth were reported, one by Mr. Hutchinson, the other by myself." This is perfectly true, but if I leave it without comment it may yet in the future lead to misapprehension. The fact is that my case of what I first called "dry mouth" had been brought before a meeting of the Neurological Society, one year previously to its being mentioned at the Clinical. I had been carefully observing the patient for at least a year before that, and the case excited great interest among the members of the Neurological, of whom Dr. Hadden is one. The merit of having been the first to notice the phenomenon and to take interest in it belongs, however, not to myself, but to one of the many who, engaged in the laborious duties of family practice, yet find zeal and leisure to give attention to the scientific aspects of medicine. It was Dr. J. S. Cotman, of the Minories, who sent the patient to me, and who allowed me to bring forward the case, as stated, at the Society. I am not sure that he had not himself taken the patient previously to a local medical society. Nearly twenty years before this the condition had been mentioned anonymously in the small type of the correspondents' column of 'one of our journals. I am not aware of any other previous notice of it, but do not doubt that some such will in the future be found. Had it not been, however, for Dr. Cotman's sagacity in observation, it is not likely we should be now engaged in a discussion as to the most appropriate name for the malarly. Yet so easy is it to follow when once the way has been shown, that upwards of ten cases have been mentioned by different observers during the three years which have elapsed since I showed thefirstpatient at the Neurological Society. Curiously enough they are all almost exactly alike. The first case was a typical one, and I believe I am justified in saying that nothing has been added to our knowledge of the nialady beyond what I stated at the meeting referred to. If there is any exception to this, it is the observation by Dr. Hadden that some relief may be obtained by the use of jaborandi; but the experience of other observers would lead us to suspect that this is not usual ; possibly it is found only in recent cases. In another sentence of Dr. Hadden's letter he writes: "At the meeting of the same Society on Nov. 3rd, 1888, the subject was again referred to by Mr. Hutchinson, and other cases were mentioned by various speakers." This, through what I am sure is an inadvertence, might seem to imply that I did not myself record any fresh case, whereas the object of my communication expressly was to bring forward another, and one of the most characteristic yet on record. In another sentence of Dr. Hadden's letter the impression might seem to be conveyed that I was anxious to disuse the Saxon term "dry nouth," and to substitute for it a more learned one. This is far from being the case, for "dry mouth" is the term which I had myself originally employed, and which I much prefer. It is to be hoped that it will remain in use in all English books, since by the majority it is far more easily remembered and recalled than such a term as "xerostomia." For einployment in other languages than English it is, however, necessary to liave a name derived from one of the dead languages. No case of "dry month" has, I believe, been yet recorded on the Continent, although the affection seems to be tolerably frequent among ourselves It may have been in part the want of a cosmopolitan name for the malady which has caused our English records regarding it to be overlooked.

At the meeting of the Clinical Society last November I suggested the name " aptyalism," and Dr. Hadden is quite correct in saying that he criticised it adversely. I was, however, before the meeting, quite familiar with all the objections which be raised, and had talked them over with several of my friends. They amount mainly to this, that "ptyalism" in Greek means "salivation" or excessive flow, and that "aptyalism" might therefore be held to imply, in strict etymology, absence of excess. In reply to this, however, physiologists, in such words as "ptyalin" $₫ \mathrm{c}$., have employed the Greek noun as applicable to saliva and its normal secretion. Such words will doubtless hold their place, and aptyalism would likewise, after a little ridicule from Greek scholars, have come to be well understood as meaning deficiency of saliva, and not the normal state of absence of excess, concerning which nobody wants to use any word. Bowing, however, to what I must be excused for saying seems to me only pedantry, I proposed at the last meeting of the Neurological Society that the word "xerostoma," a literal Greek translation of the English expression "dry mouth," should be the name employed. Dr. Hadden correctly states that, just before the meeting, when I mentioned to him the change of name I was about to propose, he said that he also, quite independently, had been intending to propose the same. I had consulted in the matter my friend Dr. Cavafy, a high authority, who, in approving of my suggestion of xerostoma, had very properly insisted on the insertion of the $i$, making it xerostomia. I am clad to find that Dr. Hadden and his classical friends also approve of the word as thus spelled. There is yet a little more to be said as regards clinical appropriateness. As a matter of clinical convenience, I believe that "aptyalism" would have been much the better word-that it would, in fact, have implied the real state of things to most persons much more explicitly. The Greek adjective in question has come into clinical use with something more than its simple meaning. Xerodermia, forinstance, is a disease of the skin with important structural changes, and is never applied to the mere absence of sweating or of sebaceous moisture; and xeroph thalmia is not merely acondition 